\title{
Aplicação de Novas Ferramentas e Abordagens Didáticas na Educação em Design
}

\author{
Application of New Tools and Didactic Approaches in Design Education
}

DELGADO, Patrícia Santos; Doutora; Universidade do Estado de Minas Gerais (UEMG) pdelgadodesign@gmail.com

FRANÇA, Rodrigo Braga; Mestrando; Universidade do Estado de Minas Gerais (UEMG)

rodrigo@notusdesign.com

DIAS, Maria Regina Álvares Correia; Doutora; Universidade do Estado de Minas Gerais (UEMG) regina.alvares@gmail.com

\section{Resumo}

Este artigo apresenta um projeto de pós-doutorado em andamento, suas bases teóricas, aplicação prática e resultados preliminares. $O$ trabalho está fundamentado em uma pesquisa de doutorado que desenvolveu uma análise crítica a respeito da atual situação da educação em design no Brasil, estudou as melhores práticas em educação em design no mundo e desenvolveu um conjunto de ferramentas didáticas para serem aplicadas por professores a fim de promover uma educação mais fluida, dinâmica e contextualizada com o cenário atual. Este trabalho apresenta a aplicação prática destes resultados em duas turmas de diferentes níveis de especialização, sendo uma de pósgraduação e outra de graduação, com alunos oriundos de diferentes cursos. Essa escolha teve o objetivo de testar as novas ferramentas e abordagens a partir de diferentes parâmetros. Os resultados preliminares mostraram que as duas turmas responderam de maneira bastante satisfatória a didática apresentada, apesar de níveis bastante diferentes de maturidade.

Palavras Chave: Educação em Design; Design Sistêmico; Complexidade; Didática.

\begin{abstract}
This paper presents a post-doctoral project, its theoretical basis, practical application and preliminary results. The work is based on a PhD thesis, which developed a critical analysis about Brazilian design education in practice, studied the best practices in design education around the world and developed a set of didactic tools to be applied by professors aiming at promoting a more fluid, dynamic and contextualized education. Now, this works presents the practical application of these results in two classes of different levels, a graduate class and an undergraduate class, with students from different courses. This choice had the goal of testing the new tools and approaches from different parameters. Preliminary results show that both classes respond in a satisfactory way to the new didactic, despite of the divergence of maturity.
\end{abstract}

Keywords: Design Education; Systemic Design; Complexity; Didactics. 


\section{Introdução}

Este artigo tem a intenção de apresentar um projeto de pós-doutorado que está sendo desenvolvido, suas bases teóricas, aplicação prática e resultados preliminares. O trabalho está fundamentado nos resultados obtidos durante a pesquisa de doutorado intitulada "Design Education in Brazil: History, Critic and New Approaches for Design Innovation", (Delgado, 2017), que teve como objetivo principal investigar como inovar no ensino do design, principalmente no contexto brasileiro. Agora, este projeto pretende dar continuidade ao trabalho desenvolvido, através da aplicação prática dos resultados obtidos.

Durante as pesquisas para o doutorado foi possível observar que no Brasil a maioria dos cursos superiores de ensino de design continuam mantendo um antigo padrão linear de educação, seguindo os métodos provenientes das escolas alemãs, como a escola de $\mathrm{Ulm}^{1}$ e a Bauhaus. Além disso, os programas valorizam mais conteúdos tecnológicos, estratégicos e econômicos, e menos os conteúdos humanos, culturais e sociais.

Esta abordagem atendeu muito bem as demandas do passado, onde o designer tinha um papel muito mais tecnicista, intencionado a atender a indústria e a produção em massa. No entanto, no mundo atual, o papel do designer vai além do projeto do produto e passa a fazer parte de um contexto bem mais amplo, incluindo o desenvolvimento de sistemas, serviços e soluções, os quais têm valorizado o homem e suas relações, a vida social, o contexto, a troca de informações e cultura. Moraes (2008) aponta que as mudanças do cenário estático para o panorama dinâmico, complexo e de difícil compreensão da atualidade elevou o desafio dos designers, que deixa de ter o carácter técnico e linear passando para um campo de qualidades intangíveis que necessita de uma maior interação transversal com disciplinas menos objetivas e exatas e mais congruentes com disciplinas sociais, no âmbito do comportamento humano.

Isso está fazendo com que os designers tenham que lidar a cada projeto com um número muito maior de variáveis, em um cenário cada vez mais complexo. Segundo Krucken (2008) o escopo do design vem sendo ampliado e evoluído, antes era centrado no projeto de produtos físicos, passa agora a uma direção que visa uma perspectiva sistêmica, sendo esta percepção sistêmica o que caracteriza e estimula a atuação do design na contemporaneidade. Lidar com essa complexidade e dinamismo exige um treinamento adequado e este deve ser feito pelas escolas.

Sevaldson (2008) afirma que expor estudantes a situações complexas é extremamente desafiador e requer habilidades que precisam ser aprendidas de forma prática. Em vários países, algumas instituições tais como o Politecnico di Torino, a Escola de Arquitetura e Design de Oslo, ou a Universidade de Toronto já estão desenvolvendo novas abordagens para o ensino de design, e essas abordagens estão trabalhando através de uma perspectiva sistêmica.

Porém, a maioria das escolas de design que trabalham com abordagens sistêmicas, somente as aplicam em cursos de pós-graduação. Em entrevistas realizadas durante o projeto de doutorado à professores de cursos de design de diferentes instituições e diferentes países, foi possível constatar que os professores consideram que não seria assertivo trabalhar a abordagem sistêmica

\footnotetext{
${ }^{1}$ A Hochschule fur Gestaltung (HfG-Ulm), foi uma das mais importantes escolas de design do mundo, que funcionou na cidade de Ulm na Alemanha entre 1953 e 1968. Depois de seu fechamento, muitos professores e estudantes foram trabalhar em diferentes partes do mundo. Assim, eles disseminaram o método de ensino da escola, que se tornou um modelo seguido tanto por escolas do Rio de Janeiro e Paris, como escolas do Chile a da Índia (Peruccio, 2010).
} 
em cursos de graduação pela dificuldade que os alunos teriam em lidar com a complexidade.

A pesquisa de doutorado apresentou como resultado uma compilação de abordagens e ferramentas didáticas verificadas ao redor do mundo que podem ser utilizadas por professores e alunos em sala de aula para que estes possam adquirir certas habilidades que os deixem aptos, ao final do curso, a gerenciar e projetar em situações complexas.

A definição das habilidades necessárias e as abordagens e ferramentas utilizadas para alcançá-las são resultado de uma pesquisa bibliográfica que investigou: o desenvolvimento da didática com ênfase no construtivismo (I); a evolução das metodologias de design (II), as novas abordagens que estão sendo praticadas em diferentes instituições no mundo (III) e o contexto da educação em design no Brasil (IV). Também são resultado de uma pesquisa prática que promoveu uma análise do contexto da educação em design, através de entrevistas com alunos e professores, acompanhamentos de aulas e análise de projetos.

O objetivo principal deste trabalho foi o de realizar a aplicação prática dos resultados obtidos, em duas turmas de diferentes níveis acadêmicos. A primeira foi uma experiência curta em uma turma de pós-graduação em design, com alunos do mestrado e do doutorado a qual será aqui descrita. E a segunda, uma aplicação mais aprofundada em uma turma de graduação em design, que está em andamento, cujo desenvolvimento será também aqui detalhado.

Acredita-se que apesar da complexidade, é possível trabalhar o pensamento sistêmico com turmas de graduação, por meio de uma didática adequada. Isso permite que os alunos iniciem o desenvolvimento das habilidades necessárias desde o início de sua formação, e assim, melhor preparados para as exigências do mundo atual.

\section{Fundamentação Teórica}

Muitos autores teorizam sobre a necessidade de uma mudança na educação em design e da necessidade de contextualização com as necessidades e demandas no mundo atual. Entretanto, poucos elaboram como fazer isso na prática. Essa adaptação deve ser feita tanto no currículo quanto na didática, provendo estudantes com uma abertura conceitual de modo que os permita ter no futuro, uma postura contextualizada com o mundo que os espera.

Moraes (2014) defende que novas escolas de design devem ser abertas, fluidas, dinâmicas e condutivas, priorizando valores humanos ao invés de técnicos, com conteúdo mais experimental do que previsível.

Bonsiepe (2012), quando discute o que seria o humanismo no design e como seria uma atitude humanista, afirma: "O humanismo projetual é o exercício das capacidades projetuais para interpretar as necessidades de grupos sociais e elaborar propostas viáveis, emancipatórias, em forma de artefatos instrumentais e artefatos semióticos" (pág. 21). No mesmo texto, o autor deixa claro que a intenção não é propor uma abordagem ingênua e não realista, mas sim de desenvolver uma consciência crítica a respeito dos problemas enfrentados pela sociedade.

Germak e DeGiorgi (2008), também discutem que a indústria, a sociedade e as escolas precisam de mentes primariamente críticas, e então assertivas, para assim serem proativas, e nunca acomodadas ou submissas. De acordo com os autores, a chave para ensinar em escolas está em relacionar e calibrar corretamente os links entre função, inspiração, inovação e adaptação ao contexto. 
Design é uma atividade flexível, capaz de conectar diferentes áreas do conhecimento. É característico das ações de design o mix interdisciplinar, o que faz do design uma área de grande potencial contemporâneo, difuso e efetivo, assim como relativo e adaptável, extraordinariamente capaz de relacionar teoria e prática, entre o possível e o viável (Celaschi, 2008).

Margolin (2014) defende que designers podem colaborar para a visualização de formas materiais para um mundo mais humano, no entanto, existe pouco conteúdo nos currículos dos cursos de design que prepare estudantes a visualizarem futuros cenários. Essa é uma tarefa difícil, uma vez que existem múltiplas visões, as quais descrevem como o mundo poderia ou deveria ser. Designers possuem competências únicas para formar planos e propostas, mas eles precisam de um contexto amplo e coerente para conduzi-los a isso.

Pourdehnad et al. (2011), afirma que o modo no qual pessoas agem em condições problemáticas depende da qualidade da abordagem que elas aplicam na situação, e essa abordagem está muito mais relacionada com a filosofia e visão de mundo do que com ciência e tecnologia. As práticas de design têm obtido consistentes resultados ao integrar a visão de mundo sistêmica em suas metodologias.

De acordo com Krippendorf (2006), algumas práticas de design têm incluído abordagens sistêmicas em seus métodos de ação de maneira interativa, levando o pensamento sistêmico para situações reais, melhorando um contexto ou objeto e ao mesmo tempo aprendendo sobre ele. Essa união do design com o pensamento sistêmico contém um enorme potencial criativo capaz de conectar melhor teoria e prática para produzir conhecimento.

Ryan (2014) define a abordagem sistêmica como um modo de trabalhar dentro de uma situação prática em um determinado contexto, agindo, refletindo, aprendendo e ao mesmo tempo, produzindo inovação em parceria com as partes envolvidas, sejam elas comunidades, fornecedores, produtores locais, entre outros. Essa abordagem produz uma perspectiva humanista das necessidades dos usuários reais, desenvolvendo habilidades capazes de dar formas tangíveis a ideias abstratas.

Cardoso (2012) defende que "a maior e mais importante contribuição que o design tem a fazer para equacionar os desafios do nosso mundo complexo é o pensamento sistêmico. Poucas áreas estão habituadas a considerar os problemas de modo tão integrado e comunicante". Essa visão de uma percepção sistêmica que estimula e caracteriza a atuação do design na contemporaneidade é reforçada por Krucken (2008) que complementa que o principal desafio do designer hoje é desenvolver ou suportar o desenvolvimento de soluções para questões de alta complexidade.

A exploração do pensamento sistêmico no ensino do design tem um desenvolvimento recente e apenas algumas instituições estão ativamente trabalhando neste campo. No entanto, existe uma considerável rede de pesquisadores e ativistas desenvolvendo atividades por meio de uma abordagem ecológica preocupada com o crescimento sustentável em uma escala global e local. Também existem algumas instituições que estão promovendo uma abordagem sistêmica educacional, assim como grupos de estudo, centros de pesquisa e revistas direcionadas a estudos futuristas.

O trabalho de doutorado de Delgado (2017) destacou alguns trabalhos relevantes de instituições de diferentes partes do mundo que aplicam práticas de ensino que enfatizam o uso do pensamento sistêmico em conjunto com o design thinking. O objetivo foi o de conhecer os métodos e as ferramentas usadas por estas instituições e os resultados obtidos. Foi possível identificar que os 
métodos de práticas de design utilizados por estas instituições têm fases e características comuns. Essas fases, assim como as principais ferramentas utilizadas foram identificadas e sintetizadas (Figura 1).

Todos os processos iniciam com uma intensa fase de pesquisa, com o objetivo de promover profundo conhecimento a respeito do contexto ou problema a ser trabalhado, do ponto de vista das partes envolvidas e do ambiente, através de experiências locais e coleta de dados quantitativos e qualitativos. Nesta fase, os designers devem entender completamente todas as atividades envolvidas e suas ações.

O design participativo é fundamental, através do envolvimento de todas as partes, fornecendo informações e contribuindo na busca de soluções. Quando possível, a imersão do designer na atividade ou ambiente deve ser incentivada, para que ele possa realmente entender aquela realidade. Este momento também é propício para a formação de parcerias através de uma metodologia cooperativa. Estas parcerias podem acontecer entre os estudantes e especialistas, pessoas públicas, empresários, membros da comunidade, entre outros. Estes parceiros devem participar de todo o processo como cocriadores e facilitadores do processo.

Figura 1. Fases comuns de abordagens que utilizam o design sistêmico

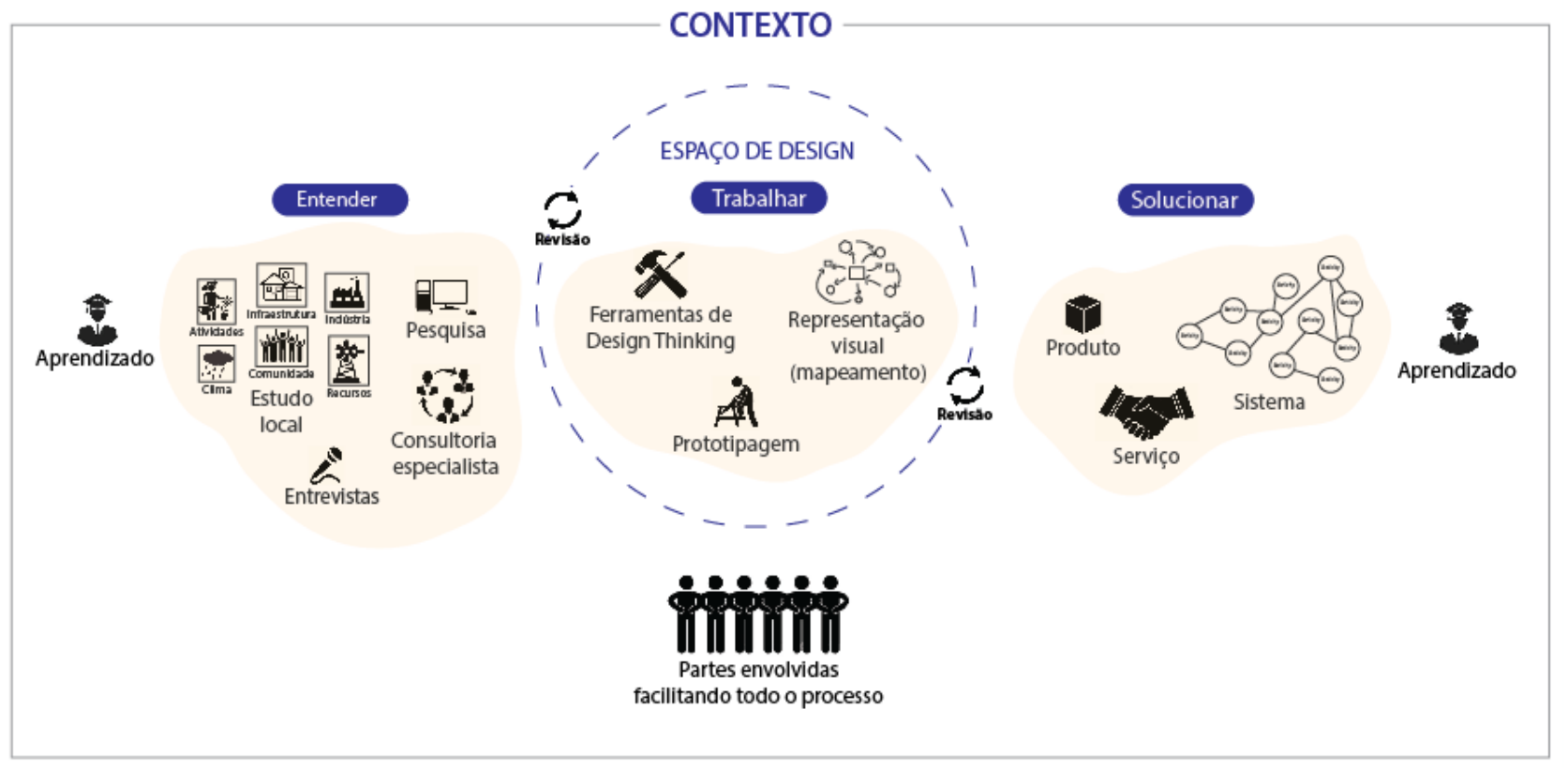

Fonte: Delgado (2017)

Com todas as informações em mãos, inicia o segundo passo no espaço de design para trabalhar os dados coletados. De acordo com Sevaldson (2008), um espaço de design deve promover uma riqueza de mídia e materiais para a representação, criando um ambiente onde os alunos aprenderão a agir rapidamente dentro de um contexto e treinarão a capacidade de manter em mente a quantidade de informações e problemas que mudam constantemente durante o processo.

O objetivo é fazer uma representação visual mais completa possível do contexto. O uso de mapas mentais permite uma visão ampliada do problema e melhora a capacidade do designer de 
trabalhar com complexidade. Quanto mais complexo e difícil o projeto, maior é a necessidade de manter muitos aspectos, ideias e representações ao longo do tempo e entre um grande número de indivíduos. Por isso a importância de uma representação gráfica aberta e compartilhada entre todas as partes envolvidas, permitindo constantes atualizações e adaptações.

Os mapas não são apenas para representar o contexto, através da análise deles surgem novas ideias ou soluções. Além disso, durante este processo, emergem novas questões, problemas ou oportunidades, tornando as propostas ainda mais ricas.

A equipe deve promover uma constante participação de pessoas envolvidas no problema e de especialistas para fazer esse processo de análise e discussão. A análise é feita de forma visual, usando como ferramentas, grandes formatos de papel, marcadores, adesivos, esboços, cartões, diferentes materiais visuais, textos e todos os modos de representação digital. É nesta fase que as ferramentas de design thinking são mais comumente usadas. A prototipagem também é uma prática nesta fase e deve ser executada da maneira mais realista possível.

No estágio de entrega da solução, o benefício é aplicado. Aqui, usa-se o termo benefício para promover uma ruptura com o pensamento tradicional, onde o projeto parte de um produto específico e gira em torno deste produto e em torno do usuário direto. Nestas novas abordagens, o projeto começa a partir da análise de um contexto e suas necessidades, e o resultado é uma nova proposta ou melhoria para um ambiente, uma empresa, um grupo de pessoas ou um determinado contexto, ou seja, o que pode beneficiar algo ou alguém. Este benefício pode vir na forma de um produto, serviço ou sistema.

Durante todas as fases, sempre há um processo de feedback da fase anterior. Durante a fase de pesquisa, a literatura e os conceitos adquiridos na fase de aprendizagem são analisados. Ao trabalhar no ambiente de design, o contexto é constantemente reanalisado e muitas vezes são necessárias novas pesquisas. Na fase de entrega da solução, o contexto e a análise estão em constante revisão.

No final, todo o processo está documentado. No caso de projetos desenvolvidos em universidades, tanto em centros de pesquisa quanto em cursos de pós-graduação, há um ganho para universidades sob a forma de artigos, teses, relatórios, que servem de bases de conhecimento para trabalhos futuros. No caso de centros independentes, observou-se a elaboração de kits de ferramentas, livros de melhores práticas e artigos para disseminação de conhecimento.

\section{Experiência Prática}

A metodologia didática apresentada no doutorado de maneira teórica foi proposta para ser posta em prática durante o pós-doutorado. O objetivo principal é o de promover inovação na educação em design, principalmente no contexto local da escola escolhida para o desenvolvimento do trabalho. Espera-se que como resultado ela se torne ainda mais contextualizada com as necessidades do mundo atual e alinhada às mais novas práticas de design já aplicadas e comprovadamente funcionais das escolas contemporâneas.

Para isso, foram elaborados dois planos de ação preliminares, um de curta duração ( 8 horas aula) na pós-graduação em design, já finalizado e outro de longa duração (32 horas aula) nos cursos de graduação em design da escola ainda em andamento. 
Para a pós-graduação foi feito um curso rápido, dividido em duas etapas, uma teórica e outra prática, de quatro horas cada. Neste curso havia uma média de 20 alunos, dos cursos de mestrado e doutorado em design e com background em diversas áreas, garantindo assim uma equipe multidisciplinar.

$\mathrm{Na}$ aula teórica foi feita uma introdução a respeito da motivação para este projeto e sua fundamentação teórica, foram apresentadas as metodologias seguidas pelas instituições pesquisadas e seus resultados. Também foi mostrada a situação atual da escola em questão, em relação ao conteúdo trabalhado e a didática, foi feita uma contextualização da escola como território local e suas características naturais, econômicas e sociais. Assim, os alunos conseguiram facilmente se conscientizarem da necessidade de uma nova abordagem e de como o design sistêmico poderia contribuir com este cenário.

Ao final foi feito um debate a respeito do tema. Os alunos se mostraram bastante interessados e participativos, apresentando vários exemplos relacionados a ações sistêmicas e de design participativo em que eles já vivenciaram ou têm conhecimento. Este debate apresentou um grau de maturidade satisfatório por parte dos alunos, que entenderam bem o que era a nova proposta, a importância de uma reformulação no ensino do design e a possibilidade de sucesso desta nova metodologia.

Assim, concluída a primeira fase do experimento de disseminação do conhecimento teórico, deu-se início a segunda parte do curso, onde foi feita uma experiência prática. Foi proposto aos alunos que se dividissem em grupos e que fizessem a construção de um cenário conhecido, usando técnicas de mapeamento. Essas técnicas foram brevemente apresentadas antes da atividade. Foi escolhido como cenário comum, o ambiente residencial, e cada grupo de alunos trabalhou um sistema interno de uma casa, como:

- Alimentação;

- Limpeza doméstica;

- Higiene pessoal;

- Animais de estimação;

- Armazenamento.

Foi pedido então que eles fizessem uma construção conceitual de uma imagem completa daqueles sistemas, a partir de seus conhecimentos prévios. Esta imagem, deveria conter informações quantitativas e qualitativas do sistema, as pessoas envolvidas, os fluxos e matéria e energia e as relações estabelecidas tanto entre os atores quanto entre os sistemas. Pediu-se que eles fizessem a representação do sistema aberto, de modo que possibilitasse a adição de informações.

A experiência durou as quatro horas restantes, foi feita em um ambiente propício, onde os alunos tiveram a liberdade de se movimentarem livremente, mudando a configuração do espaço de modo a se adequar as necessidades de trabalho e comunicação e também houve a utilização de material criativo, como canetas coloridas, grandes formatos de papéis, post-it, etc. (Figura 2). Cada grupo fez o trabalho de maneira diferenciada de acordo com o material que tinham disponível. 
Figura 2: Grupo de alunos de pós-graduação trabalhando o mapeamento sistêmico.

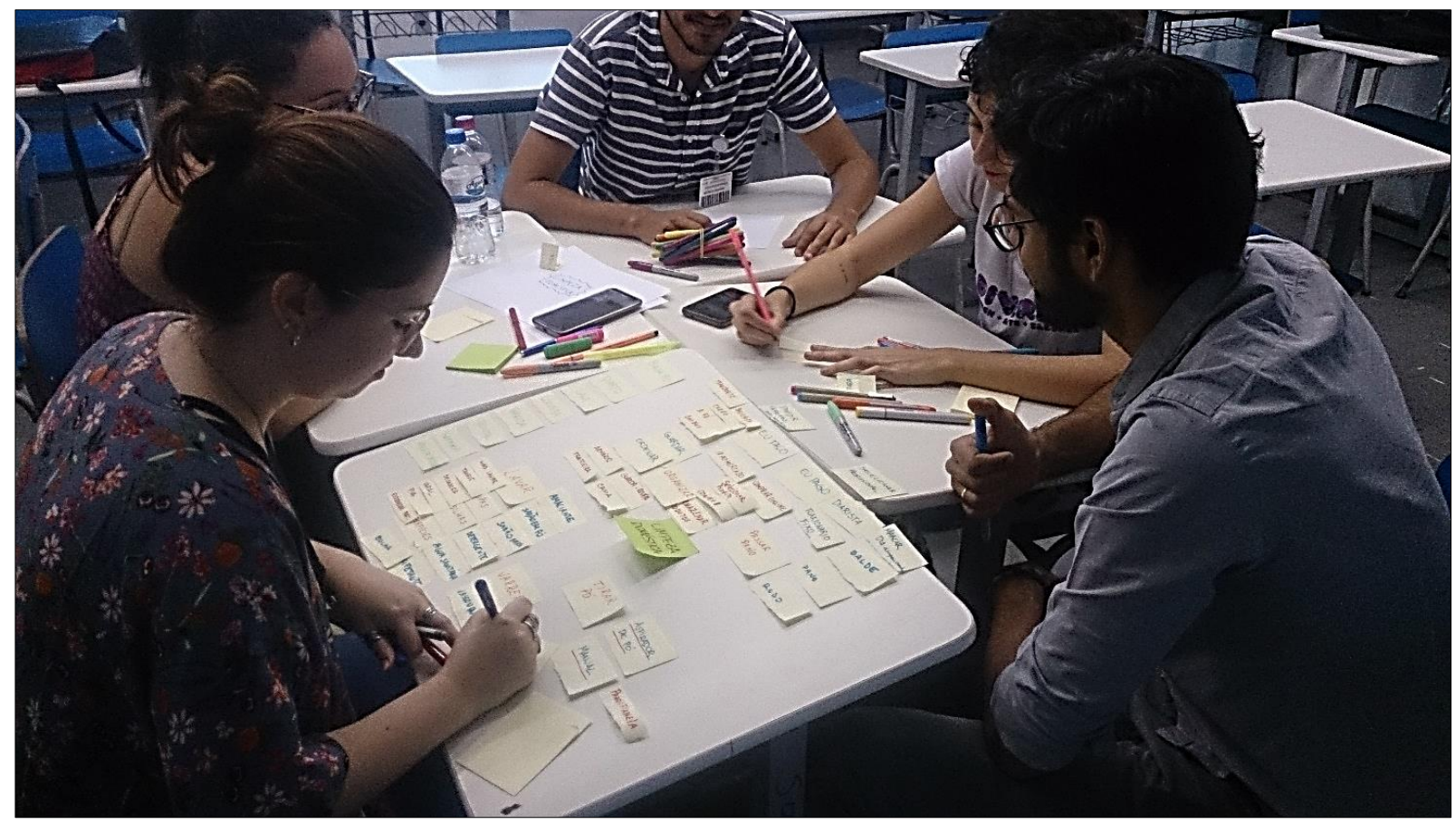

Fonte: os autores.

Os alunos completaram este mapeamento prévio e ao final, novamente, houve um debate a respeito da atividade para discussão das percepções, dificuldades, curiosidades e ganhos. Esta experiência na pós-graduação foi de curta duração em duas etapas, a primeira com o objetivo de apresentar a metodologia sistêmica, observar e verificar como os alunos reagiriam a proposta; e a segunda etapa de experimentação prática, onde os alunos tiveram o primeiro contato com a prática projetual proposta tendo a oportunidade de vivenciar e discutir, ainda que de forma preliminar, aspectos práticos da metodologia apresentada.

Já a experiência com alunos de graduação, foi elaborada em forma de disciplina optativa, intitulada "Design para cenários complexos na prática". Esta disciplina se encontra em andamento na data da construção deste artigo, e conta com 30 alunos dos diferentes cursos de design da instituição: design de produtos, design gráfico, design de ambientes e licenciatura em educação artística. O objetivo da disciplina é o de apresentar aos alunos um modo não linear de projeto que os permita lidarem com problemas de projeto complexos através do uso de uma abordagem sistêmica.

A disciplina está sendo desenvolvida durante o presente semestre letivo, com carga horária de 16 aulas, revezando entre conteúdos teóricos e atividades práticas. As duas primeiras aulas foram teóricas com conteúdo metodológico e explicações similares aquelas apresentadas a pósgraduação. Ao final destas aulas foi solicitado que os alunos relatassem suas primeiras impressões a respeito da disciplina (Figura 3 ). 
Figura 3: Primeiras impressões dos alunos da turma de graduação

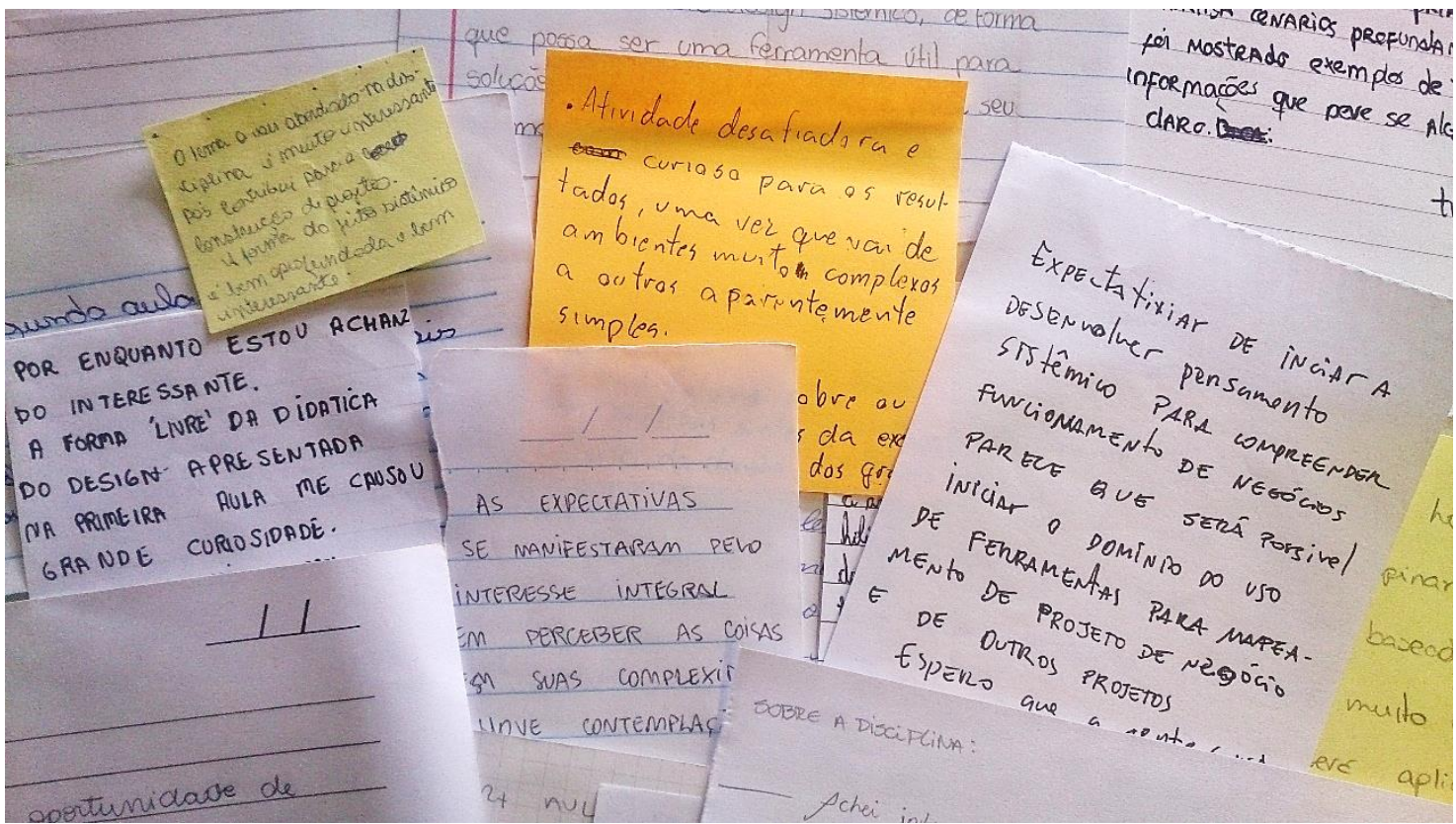

Fonte: os autores

A terceira aula teve uma abordagem prática e foi bem semelhante com a experiência da pósgraduação. Porém, neste caso o cenário escolhido para o desenvolvimento do exercício prático foi a própria Escola de Design e suas diferentes áreas e sistemas internos. Os alunos foram divididos em grupos de cinco integrantes cada, sendo propositalmente balanceados para uma heterogeneidade de cursos e períodos. Os sistemas definidos para trabalho foram:

- Cantina;

- Papelaria;

- Biblioteca;

- Laboratório de tipografia;

- Oficina da madeira;

- Manutenção.

Nesta aula, os alunos tiveram a oportunidade de realizar, a partir de seus conhecimentos prévios, um mapeamento preliminar dos contextos. O processo aconteceu de maneira idêntica ao trabalho desenvolvido na pós-graduação, em um ambiente propício, com liberdade de reconfiguração do espaço e material adequado. A diferença é que desta vez os alunos tomaram conhecimento do tema com uma semana de antecedência e também receberam uma explicação mais cuidadosa a respeito de técnicas de mapeamento, e demonstração de exemplos.

A seguir algumas imagens da prática (Figura 4): 
Figura 4: Alunos de graduação trabalhando o mapeamento sistêmico
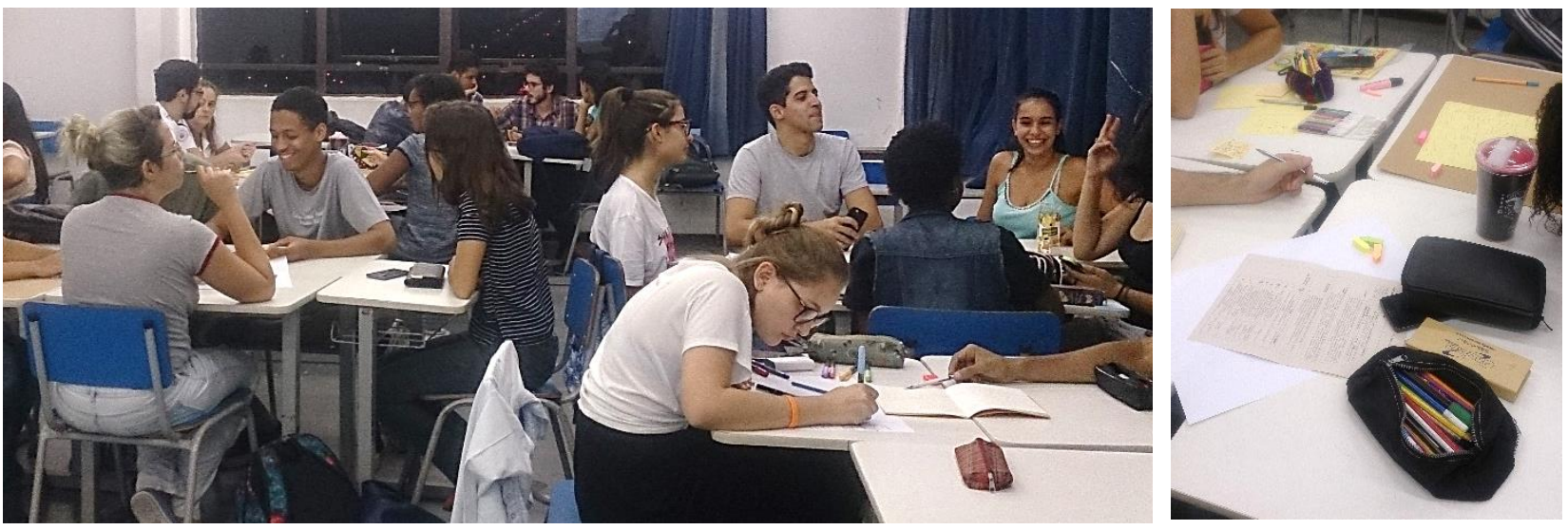

Fonte: os autores

\section{Resultados}

O trabalho promoveu uma experiência da aplicação de técnicas e ferramentas didáticas no ensino para duas turmas de diferentes níveis de conhecimento, mas que receberam a mesma aula teórica e a mesma atividade prática.

Observou-se que, após a primeira apresentação, os alunos da pós-graduação souberam entender muito melhor a proposta e sua importância, apresentaram um debate muito mais maduro a respeito do tema, sendo capazes de apresentar exemplos e questionamentos pertinentes. Os alunos da disciplina ofertada na graduação também entenderam e demonstraram interesse pelo tema, mas de maneira geral, apresentaram uma certa preocupação por considerarem o tema muito complexo, demostrando inseguranças e dúvidas quanto ao resultado final do trabalho.

Em relação a atividade prática, os alunos da pós-graduação conseguiram ser mais livres na construção gráfica do sistema, com cada grupo apresentando propostas diferentes e mais direcionadas aos sistemas apresentados. Demonstraram um pensamento muito mais aprofundando e complexo a respeito dos elementos do sistema, complementando e expandindo as informações de tal forma que começaram a se sentirem perdidos pelas inúmeras possibilidades e quantidades de informações levantadas e propostas, precisando de intervenções para auxiliar na definição dos pontos mais relevantes a serem observados considerando o foco inicial e objetivo do trabalho.

Os alunos da graduação ficaram mais presos aos exemplos dados no início da aula, e todos os grupos se portaram de maneira semelhante, iniciando a construção de seus mapas de maneira bastante similar. Porém, após uma primeira intervenção eles conseguiram pensar e propor formatos diferentes de mapas e começaram a fazer imagens mais particulares e direcionadas ao contexto que estavam trabalhando. Ao contrário da turma de pós-graduação, estes alunos apresentaram um pensamento mais simples e mais focado ao problema, precisando de mais estímulos para ampliarem as informações e expandirem os elementos do sistema. O próprio pensamento de sistema, em contraposição ao pensamento de elementos pontuais e isolados, foi um desafio para os alunos.

Quanto ao trabalho em grupo, observou-se que a mistura de alunos com experiências e conhecimentos diferentes foi muito enriquecedor, não só pela troca de informações, mas também 
para aumentar o nível do debate. Além de aprenderem novos pontos de vista e lidarem com ideias e informações diferentes daquelas que eles já tinham, os alunos também vivenciaram a possibilidade de ensinar algo novo aos colegas de outras disciplinas. Essa troca de conhecimento reforça o aprendizado e trabalha a empatia, a capacidade de comunicação e negociação e a flexibilidade para aceitar o novo.

Apesar de ter sido comunicado aos alunos que eles teriam liberdade para reconfigurar o espaço de sala de sala e ter havido incentivo para usos de materiais diversos em tamanhos, formatos e características, pouco foi modificado em relação a configurações conhecidas e uso de recursos básicos, apenas mudanças simples como a união de carteiras foi observada, não saindo do lugar comum.

Pôde-se perceber que para os alunos de pós-graduação, em sua maioria, houve frustração por terem uma experiência tão curta que não permitia a continuidade do trabalho. Apesar disso eles puderam experimentar uma nova ferramenta e foram direcionados a continuarem a trabalhar através de uma perspectiva sistêmica. A aplicação e uso de algumas ferramentas, como a construção de mapas mentais foram compreendidas e absorvidas mais facilmente como forma de lidar com a complexidade e com o dinamismo da contemporaneidade. Os alunos da pós-graduação também evidenciaram a importância de trabalharem em grupo e em situações reais para a formação do designer.

Os alunos da graduação se mostraram entusiasmados com a continuidade do projeto, que irá trabalhar nos contextos e sistemas propostos ao longo do semestre, através do mapeamento visual, da identificação de problemas e oportunidades de projeto e desenvolvimento de soluções. O objetivo é que eles possam trabalhar com situações reais e em contato com as pessoas envolvidas (stakeholders) para então avançarem até a fase do projeto de possíveis soluções.

\section{Conclusão}

A experiência apresentada neste trabalho mostrou que apesar de não terem o mesmo nível de maturidade e conhecimento que os alunos de pós-graduação, os alunos de graduação, fazendo o uso das ferramentas propostas e com o direcionamento adequado são capazes de apresentar resultados satisfatórios. A experiência de trabalhar de modo aberto, por meio de um pensamento sistêmico, no início da formação destes alunos, dá a eles a oportunidade de trabalharem suas habilidades para lidarem com situações complexas de modo muito mais suave e com um tempo maior. Assim, ao final de sua formação, eles serão capazes de gerenciar melhor os desafios que irão enfrentar, apresentando resultados mais contextualizados e inovadores, considerando o homem, seu ambiente e as relações que são estabelecidas em meio a suas diversas ações.

Estes resultados são preliminares, e a aplicação na graduação será continuada durante a pesquisa de pós-doutorado. Espera-se que ao final, possa ser proposta uma nova metodologia à referida escola, a ser aplicada no currículo regular dos seus cursos, e que posteriormente possa servir de modelo para outras escolas. Essa mudança da abordagem linear atual para uma abordagem sistêmica poderá trazer um resultado positivo, que irá afetar não só os estudantes, mas também professores e toda comunidade acadêmica e local. Uma mudança positiva na educação resulta em profissionais preparados para fazer também uma mudança positiva na sociedade e seu contexto. 


\section{Referências Bibliográficas}

BONSIEPE, G. Design, Cultura e Sociedade. São Paulo: Blucher, 2012.

CARDOSO, Rafael. Design para um mundo complexo. São Paulo: Cosac Naify, 2012

CELASCHI, F. Design as Mediation between Areas of Knowledge. The integration of knowledge in the training of contemporary designers. In: In: GERMAK, C. Man at the Center of the Project Design for a New Humanism., v.1, pp. 19-31. Turim: Allemandi e C, 2008.

DELGADO, P.S. Design Education in Brazil: History, Critics and New Approaches for Design Innovation. Tese apresentada ao Programa de Gestão de Sistemas e Design Industrial do Politécnico di Torino. Turim, 2017.

GERMAK, C.; De Giorgi, C. Exploring Design. In: GERMAK, C. Man at the Center of the Project Design for a New Humanism. v.1, p 53-70. Turim: Allemandi e C, 2008.

KRIPPENDORFF, K. The Semantic Turn: A New Foundation for Design. Boca Raton: CRC/Taylor \& Francis, 2006.

MARGOLIN, V. I. Design e Risco de Mudança. Vila do Conde: Verso da História, 2014.

MORAES, Dijon de. Design e complexidade. In: MORAES, D.; KRUCKEN, L. (org.). Cadernos de Estudos Avançados em Design: transversalidade. Belo Horizonte: Santa Clara, Editora da UEMG, 2008.

MORAES, D. Design's postgraduate courses in Brazil: scenarios and perspectives. Estudos em Design (online). v. 22, n. 3. Rio de Janeiro, 2014.

PERUCCIO, P.P. Torino 1969-2009: Quarant'anni di Design e Sapere Politecnico. In. Op. Cit. Selezione Della Critica d'Arte Contemporanea. n. 137, p. 29-41. Napoli: Electa Napoli, 2010.

POURDEHNAD, J.; Wexler, E.R.; Wilson, D.V. Systems \& Design Thinking: A Conceptual Framework for their Integration. In: International Society for the Systems Sciences (ISSS). $55^{\circ}$ Conferência Annual: "All Together Now: Working Across Disciplines". Universidade de Hull, Hull, UK, 2011.

KRUCKEN, Lia. Competências para o design na sociedade contemporânea. In: MORAES, D.; KRUCKEN, L. (org.). Cadernos de Estudos Avançados em Design: transversalidade. Belo Horizonte: Santa Clara, Editora da UEMG, 2008.

RYAN, A. A. Framework for Systemic Design. Form Akademisk - Research Journal of Design and Design Education. v .7, n. 4, art. 4, pp. 1-14, 2014.

SEVALDSON, B. A system approach to design learning. In: Systemisches Denken und Integrales Entwerfen / System thinking and Integral Design. Offenbach: Achim Menges, Präsident der Hochschule für Gestaltung Offenbach am Main, 2008. 